\title{
Breast Cancer risk factors and screening practices Among Women Attending Family Health Centers in Cairo Governorate
}

\author{
Eman M. Seif El-Nasr \\ Lecturer of Community Health Nursing, Faculty of Nursing, Cairo University
}

\begin{abstract}
In Egypt, breast cancer ranks the first among cancer affecting females. Aim: The aim of this research was to assess breast cancer risk factors and screening practices among women attending Family Health Centers. Design: A descriptive exploratory research design was adopted in this research. Setting: data were collected from two family health centers Ein EL Sera and Abo EL-Sooud family health centers. Sample: A purposive sample was used as all available women in selected family health centers and who fulfill the inclusion criteria were included in this study. Tool for data collection: A breast cancer structured interview questionnaire was developed by researchers. It included three parts; Part I: Demographic characteristics, obstetric history and Knowledge about breast cancer. Part II: Risk factors of breast cancer. Part III: Breast cancer screening practices and its barriers. Results: revealed that, mean age was $39.42+12.5$ years and mean age of menarche was $12.7 \pm 1.06$ years. It was found that, $73.3 \%$ of the study sample did not have any knowledge about breast cancer. The most common risk factors for breast cancer were $22.5 \%$ had previous family history of breast cancer and 55.4\% were using hormonal contraceptive methods. While 45.4\%, 80.8\% and 73.7\% did not have any knowledge about breast self-examination, mammography and clinical breast examination by doctors or nurse respectively. Also, a statistically significance negative correlation was found between age of females and their practicing of breast self- examination and clinical breast examination. A statistically significance correlation was found between family history of breast cancer and practicing breast self-examination, clinical breast examination and mammography. Conclusion: The study concluded that, the common breast cancer risk factors identified were; age, education, family history, knowledge about breast cancer are significantly related with screening practices. Also screening for breast cancer is important in the early detection through various methods as breast self examination, clinical breast examination and mammography. Recommendations: Based on the findings of this research the following are recommended; educational program is needed to increase women' awareness about breast cancer screening practices and how and when to do it.
\end{abstract}

Key words: Risk factors, obesity, screening practices

\section{Introduction}

Breast cancer is the most frequent cancer in women worldwide. It is one causes of cancer mortality in women and constitutes $15 \%$ of female cancer deaths. The incidence rates of breast cancer are increasing in most countries at a younger age than ever before, and these changes are usually greatest where the rates had been previously low [1]. It has been identified as a major public health problem in both developed and developing nations because of its high incidence-prevalence, the over-burdened health system and direct medical expenditure [2].

The high incidence of breast cancer necessitates the need for early detection because this would increase the treatment options available to affected women and thereby improve survival rates [3]. Some studies have shown that in most of the developing nations and resource constraint settings, breast cancer is diagnosed in advanced stages of the disease when compared with developed nations and thus has a poor outcome and high fatality rate [4,5].

There are many known risk factors for breast cancer, some of these cannot be changed, but some can. About $5 \%$ to $10 \%$ of breast cancer cases are thought to be hereditary, caused by gene changes (mutations) inherited from a parent. Being a woman is the main risk factor for developing breast cancer. Also, breast cancer risk increases as a woman gets older, women who have a close blood relative with this disease have a higher risk for breast cancer. A woman with cancer in one breast has an increased risk of developing a new cancer in the other breast or in another part of the same breast. Women who had radiation to the chest for another cancer as a child or young adult are at a much higher risk than those who did not [6]. 
Risk for breast cancer increased in women who use or recently used combined post-menopausal hormone therapy for many years. Also women who use hormonal contraceptives methods are slightly higher their risk than a women who never used them. Women with denser breast tissue have a higher risk of breast cancer. Not having children or having them later in life (after age 30) puts a woman at slightly higher risk. More menstrual cycles might slightly higher the risk of breast cancer if a woman started menstruation early or went through menopause late. Some studies suggest that breastfeeding may slightly lower breast cancer risk. Being more active might lower the risk of breast cancer, also overweight and obesity raises the risk of having breast cancer, especially for women after menopause. Clearly linked to increased risk is the amount of alcohol taken [6].

Reduction in mortality from breast cancer depends to a large extent on interventions aimed at early detection and treatment, including breast self-examination, clinical breast examination, and mammography. Lack of early detection programs is the primary reason for the escalation of the mortality rate from breast cancer in developing countries [7]. Methods for early detection must be considered the best second choice for reducing the mortality, amongst which breast self-examination, clinical breast examination by the treating physician, as well as ultrasound and mammography, are the secondary preventive methods used for screening in the early detection of. According to the American Cancer Society, breast self-examination is an option for women starting from the early 20's [8].

Breast self-examination is a check-up that a woman does by herself at home to look for changes or problems affecting the breast tissue. It is still recommended as a general approach to increasing breast health awareness and thus potentially allow for early detection of any anomalies because it is free, painless and easy to practice [9]. Also recommends that women, starting from the age of 20 years should be educated on the pros and cons of performing monthly breast self-examination. For women to present early to hospital they need to be "breast aware"; they must be able to recognize symptoms of breast cancer [10].

A clinical breast examination is a physical examination of the breast done by a health professional. Clinical breast examinations are used along with mammograms to check women for breast cancer and other breast problems. Mammography is the only screening tool proven to reduce breast cancer mortality, screening mammography can reduce breast cancer mortality by $22-35 \%$ for women aged 50 years or older. In Egypt, although facilities for mammographic screening are available in the major governmental and private hospitals, there is no nationwide systematic program for breast screening at the present time. Various factors have been reported to have an effect on screening rates, including women's socioeconomic status, their knowledge of risk factors, and having a family history of breast cancer. Barriers to breast cancer screening have been identified in a variety of populations and grouped under three main categories; personal, economic, and health care service barriers [7].

Breast cancer is a major health problem for the women and the community. Community and general nurses are the primary teams among health care professionals who are easily approachable and may act as the potential health educator. The preventive services delivered by nurses in the form of health assessment, screening, and counseling can be integrated into comprehensive health promotion and protection activities at the community level. The desired initial step for the community health nurse is to assess women's background knowledge and attitudes prior to the preparation and participation in conducting breast cancer teaching programs [11]. Community health nurses could make a positive impact in the field of breast cancer diagnosis. They can assess the patients' physical and emotional status. They could make door to door visits and could well utilize this visit to teach women about breast self-examination, they have a better opportunity to develop a rapport with the women and their relatives, and impart some knowledge about the breast cancer. The nurses constitute an important source of information within their social network, and can possibly serve as a first line of communication between the women and the doctor [12].

In Egypt, breast cancer is the most prevalent cancer among women, representing $19 \%$ of total cancer cases. Currently, it is the leading cancer among Egyptian females, and its incidence is projected to increase by 1-2\% every year. The disease is usually diagnosed at an advanced stage among the Egyptian women. Research has shown that distribution of breast cancer is within the younger age group of Egyptian patients, the majority of cases occurring between 30-60 years of age. The median age at diagnosis is 49 years, one decade younger than the corresponding age in Europe and North America [7]. The study done by Ibrahim, Khaled, Mikhail, Baraka \& Kamel [13] to investigate cancer incidence rates at national and regional level of Egypt, revealed that, breast cancer accounted for $32 \%$ among women where breast cancer occupied the second rank of all types of cancer. Early detection of breast cancer can lead to prevention as much as possible and a better prognosis of breast cancer.

Minimal attention is being paid to primary prevention of breast cancer. Women did not frequently practice breast cancer screening procedures. As improving breast cancer screening practices aims to reduce morbidity and mortality rates. Findings of this study will provide supportive data about risk factors for breast cancer, screening practice and barriers for screening so this data can be used to enhance heath intervention program related to breast 
cancer risk factors and screening practices. Therefore, this study aimed to assess breast cancer risk factors and screening practices among women attending Family Health Centers.

The aim of the study was to assess breast cancer risk factors and screening practices among women attending Family Health Centers. Results of this study answered the following questions: 1- What are breast cancer risk factors and screening practice used among Women attending Family Health Centers? 2- Is there a relationship between demographic characteristics of women and screening practice? 3- Is there a relationship between risk factors of breast cancer and screening practices?

\subsection{Research Design}

\section{Subjects and Methods}

A descriptive exploratory research design was adopted in this research. This design is used to provide a picture of a phenomenon as it naturally happens and to investigate the full nature of the phenomenon and other factors related to it [14].

\subsection{Setting}

Cairo governorate is divided into four directions; North, South, East and West, by using simple random sample technique, one direction was selected from these four directions. This direction was the "South". There are ten districts in this direction, one district was selected randomly. This district was Misr El kadima and includes four family health centers; Al-Zahra, Amr Ibn Al-Aas, Ain Alsira and Abou El Saud family health centers serving a huge number of populations (262 thousand and 916 hundreds individual). Two family health centers were selected randomly Ein EL Sera and Abo EL-Sooud family health centers. Those two family health centers are providing a lot of health services including; vaccination, maternal and child health, family planning, antenatal care, family planning, premarital examination and dental care [15].

\subsection{Sample}

A purposive sample was used as all available women in selected family health centers included in this study. The total number of the sample was 240 women from the two family health centers and who fulfill the inclusion criteria. Inclusion criteria were; women at age between 20-60 years and free from breast cancer.

\subsection{Tool for Data Collection}

A breast cancer structured interview questionnaire was developed and filled by the researcher after extensive review of related literature. It included three parts;

Part I: Description of the study sample included: a) Demographic characteristics: as age, education, occupation, marital status, monthly income and place of residence. B) Obstetric history: age at menarche, age at first delivery and age at menopause. C) Knowledge about breast cancer: having knowledge about breast cancer and source of knowledge.

Part II: Risk factors of breast cancer: as previous history of breast problems, types of previous breast problem, family history of breast cancer, family members with breast cancer, history of hysterectomy and age at hysterectomy, hormonal contraceptive methods, hormonal replacement after menopause, history of breast feeding, practicing exercises and body mass index.

Part III: Breast cancer screening practices and it's barriers: breast self-examination (having knowledge about breast self examination, time of practicing breast self-examination, cause of not doing breast self-examination), mammography (having knowledge about mammography, time for doing it, causes for not doing it and last time of mammography), clinical breast examination by doctors or nurses (time for clinical breast examination, causes for not seeking clinical breast examination).

\subsection{Tool Validity}

Tool was submitted to a panel of five experts in the field of oncology, maternity nursing and community health nursing and medicine to test the content validity. Modification was carried out according to the panel judgment on clarity of sentences and appropriateness of content.

\subsection{Ethical Consideration}

An official permission was granted from the directors of the two family health centers in Ain Alsira and Abou El Saud family health in the area of Misr El kadima. The researcher introduced herself to the women who met the criteria of inclusion, then informed them about the purpose of this research in order to obtain their 
Breast Cancer risk factors and screening practices...

acceptance to participate in this research. The researcher ensured that, the research posed no hazards on their health. All events that occurred during data collection were considered confidential. All women were informed that, participation in the research is voluntary. Oral consent was obtained from females who were willing to participate in the research.

\subsection{Pilot Study}

A sample of $10 \%$ of the women who met the criteria of inclusion was included in the pilot study in order to assess the feasibility and the clarity of the tool and determine the needed time to answer the questions. Pilot study revealed that the average length of time needed to complete the questionnaire by researcher was approximately 30 minutes. Pilot sample was included in the study as minimal changes were carried out.

\subsection{Procedures}

Data was collected through a period of 6months from August 2015 till January 2016, two days per week from $10 \mathrm{am}$ till $12 \mathrm{pm}$. After the females had been fully informed and agreed to participate in the study, the researcher started to collect data through structured interview. Data collected through 1) personal interview to collect data related to sociodemographic and history, 2) assessment of female's body mass index. Interview the sample took about 45 minutes for each one.

\subsection{Statistical Analysis}

Collected data were coded and tabulated using personal computer. Statistical package for social science (SPSS) version 16 was used. Descriptive as well as inferential statistics were used to answer research question. Relations between different numerical variables were tested using Pearson correlation. Probability (p-value) less than 0.05 was considered significant and less than 0.001 was considered as highly significant.

\section{Results}

Findings of this descriptive exploratory research will be presented in four main parts: 1) description of the study sample; a) Demographic characteristics, B) Obstetric history, C) Knowledge about breast cancer. 2) Risk factors of breast cancer 3) Breast cancer screening practices and its barriers 4) Correlation between risk factors of breast cancer and screening practice.

\section{Part I: description of the study sample:}

a) Demographic characteristics: Regarding the age of the study sample, $16.6 \%$ aged from 30 to less than 40 years, $17.5 \%$ aged from 50 to less than 60 years, $26.7 \%$ aged from 40 to less than 50 years, while $32.1 \%$ of the study sample aged between 20 to less than 30 years, and only $7 \%$ aged between 60 years with a mean age $39.42+12.5$ years. As for marital status, $55.4 \%$ of the study sample was married, $24.2 \%$ were single, $12.9 \%$ were widowed and only $7.5 \%$ were divorced. Results revealed that, more than half of the study sample (54.6\%) was housewives, $42.5 \%$ were employees, and $2.9 \%$ were retried.

In relation to educational level, $27.1 \%$ of the study sample had secondary school education, $26.3 \%$ had diploma education, $22.5 \%$ were unable to read and write and $8.3 \%, 7.5 \% \& 3.3 \%$ respectively had primary, preparatory school education and university education while only $5 \%$ can read and write. The majority of the study sample (89.6\%) had a monthly income less than 1000 Egyptian pounds while only $7.1 \%$ had a monthly income ranging from 1000 to less than 2000 Egyptian pound and only 3.3\% of them had a monthly income ranging from 2000 to 3000 Egyptian pound with a mean $649.54 \pm 425.260$ Egyptian pound. More than half $(57 \%)$ of the study sample were from rural areas.

B) Obstetric history: results revealed that, $30.4 \%$ of the study sample had their menarche at age from 13 to less than 14 years, $29.2 \%$ had their menarche at the age of 14 years, $20.8 \%$ had their menarche at the age of 12 years to less than 13 years and $19.6 \%$ had their menarche at the age of 11 years to less than 12 years with a mean $12.7 \pm 1.06$ years. It was found that, $54.1 \%$ of the study sample delivered for the first time when they were 16 years to less than 20 years while $45.9 \%$ aged 20 to less than 25 years when they delivered for the first time with a mean age $20.3 \pm 2.54$ years. As for menopause, 26.7\% passed through menopause at the age of 55 to 56 years, $31.6 \%$ had their menopause by the age of 49 year to less than 51 years, $26.7 \%$ had their menopause by the age of 51 years to less than 53 while only $15 \%$ passed through the menopausal period at the age of 53 years to less than 55 years with mean of $52.44 \pm 2.42$ years. 
C) Knowledge about breast cancer: it was found that, $73.3 \%$ of the study sample did not have any knowledge about breast cancer. As for the study sample who had knowledge about breast cancer revealed that their sources of knowledge were; T.V. \& radio (17.5\%), family \& friends (16.7\%), newspapers \& magazines $(14.2 \%)$ and only 5\% had their knowledge from doctors and nurses.

Part II: Risk factors of breast cancer: only $23.3 \%$ had previous breast problems, these problems were in the form of benign lymph nodes (16.1\%), breast collection (67\%), abscess (37.5\%) and nipple secretions (5.3\%). As for the family history of breast cancer, $77.5 \%$ had no family history of breast cancer and only $22.5 \%$ had previous family history, those who had family history of breast cancer indicated that, their mothers were the affected person (38.9\%), $22.2 \%$ indicated that the affected person were their aunts (mother's sister), their sisters were affected (20.4\%) and $18.5 \%$ revealed that their grandmothers were the affected person. It was found that, only $5 \%$ of the total sample had hysterectomy, $75 \%$ of them had hysterectomy at the age of 50 years while $25 \%$ at the age of 55 to less than 60 years. Results revealed that, $55.4 \%$ were using hormonal contraceptive methods and no one of the study sample took hormonal replacement therapy after menopause. Three quarter (75.2\%) of the study sample breast feed their children for 2 years. Regarding study sample body mass index, it was found that, $50.4 \%$ of the study sample was overweight (BMI: $25-29.9 \mathrm{~kg} / \mathrm{m}), 8.8 \%$ were obese $(\mathrm{BMI}>30 \mathrm{~kg} / \mathrm{m}$ ) and the rest had normal body mass index. Only $28.3 \%$ of the study sample was practicing exercises.

Part III: breast cancer screening practices and its barriers: regarding the study sample's knowledge about methods of breast cancer screening and its barriers, results revealed that, $45.4 \%$ did not have any knowledge about breast self-examination, $75.8 \%$ never practiced breast self-examination, and $70.7 \%$ of those who were practicing it were doing it once per month, while $29.3 \%$ were doing breast self-examination only in the presence of complain. Regarding barriers for not practicing breast self-examination, results revealed that $83 \%$ did not have knowledge was the main cause for not doing breast self-examination, while $7.7 \%, 9.3 \%$ respectively identified that fear from discovering cancer and embarrassment were the reasons for not practicing breast self-examination.

The majority of the study sample $(89.6 \%$ ) did not practice mammography where $80.8 \%$ did not have any knowledge about this procedure. For those who practiced mammography it was done 2 years ago while $48 \%$ performed it since 3 years. The main causes for not doing mammography were; embarrassment from the procedure (40.5\%), fear from painful sensation (34.4\%), very expensive procedure $(29.3 \%)$, fear from cancer diagnosed (20.9\%), fear from exposure to radiation (29.3\%), and husband refusal $(17.7 \%)$.

Results revealed that, $73.7 \%$ of the study sample did not have clinical breast examination by doctors or nurses while only (26.3\%) of them had clinical breast examination. Regarding time of clinical breast examination, $93.7 \%$ doing it if there is any problem and only $6.3 \%$ were doing it every year. The result also revealed that, the main causes for not seeking doctors or nurses for clinical breast examination were embarrassment $(71.8 \%)$, husbands refusal (34.5\%), and fear from being diagnosed by breast cancer and death $(96 \%)$, while $22.5 \%$ revealed that financial status was the main cause for not doing clinical breast examination by doctors or nurses, $15.3 \%$ due to inaccessible of this service, $12.4 \%$ mistrust and $19.2 \%$ expressed that no need for doing this examination.

\section{Part VI: Correlation between risk factors of breast cancer and screening practices:}

Table (1) revealed a statistically significance negative correlation between age of the study sample and their practicing of breast self- examination $(\mathrm{p}=0.01)$ and clinical breast examination $(\mathrm{p}=0.02)$, while no statistically significant correlation was found between age and practicing mammography $(\mathrm{p}=0.33)$. As for the education, a statistically significant positive correlation was found between study sample's education and practicing breast selfexamination and mammography $(\mathrm{p}=0.000 \& \mathrm{p}=0.007)$ respectively. Also, a statistically significance correlation was found between family history of breast cancer and practicing breast self-examination, clinical breast examination and mammography $(\mathrm{p}=0.000, \mathrm{p}=0.000 \& \mathrm{p}=0.000)$ respectively. While no statistically significance correlation was found between the income of the study sample and practicing breast self-examination, clinical breast examination and mammography.

Table (2) revealed a statistically significant positive correlation between study sample's knowledge about breast cancer and practicing breast self-examination $(\mathrm{p}=0.000)$, clinical breast examination $(\mathrm{p}=0.000)$ and mammography $(\mathrm{p}=0.000)$. No statistically significant correlation was found between study sample who received hormonal contraceptive and had hysterectomy and their practice of breast self-examination, clinical breast examination and mammography. A statistically significant positive correlation was found between women who had previous breast problems and practicing breast self-examination $(\mathrm{p}=0.0)$, mammography $(\mathrm{p}=0.000)$, clinical breast examination $(\mathrm{p}=0.002)$. 
Results clarified a statistically significant positive correlation between the age of the study sample at first delivery and practicing breast self examination $(\mathrm{p}=0.000)$ while no statistically significant correlation was found between the age of the study sample at first delivery and practicing clinical breast examination and mammography. No statistically significant correlation was found between age of the study sample at menarche and menopause and their practicing of breast self-examination, clinical breast examination and mammography (table 3).

Table (1): Correlation between demographic characteristics and screening practices among the study sample

\begin{tabular}{|l|c|c|c|c|c|c|}
\hline \multirow{2}{*}{$\begin{array}{c}\text { Socio-demographic } \\
\text { characteristic }\end{array}$} & \multicolumn{2}{|c|}{ Breast self examination } & \multicolumn{2}{c|}{ Clinical breast examination } & \multicolumn{2}{c|}{ Mammography } \\
\cline { 2 - 7 } & $\mathrm{r}$ & $\mathrm{p}$ & $\mathrm{r}$ & $\mathrm{p}$ & $\mathrm{r}$ & $\mathrm{p}$ \\
\hline Age & -0.153 & $0.01^{*}$ & 0.149 & $0.0^{*}$ & 0.063 & 0.33 \\
\hline Education & 0.309 & $0.000^{* *}$ & 0.008 & 0.9 & 0.172 & $0.007^{* *}$ \\
\hline Income & 0.112 & 0.08 & -0.039 & 0.54 & 0.022 & 0.74 \\
\hline Family history & 0.418 & $0.000^{* *}$ & 0.382 & $0.000^{* *}$ & 0.473 & $0.000^{* *}$ \\
\hline
\end{tabular}

Table (2): Correlation between risk factors of breast cancer and screening practices among the study sample

\begin{tabular}{|l|c|c|c|c|c|c|}
\hline \multirow{2}{*}{ Risk factors } & \multicolumn{2}{|c|}{ Breast self examination } & \multicolumn{2}{c|}{ Clinical breast examination } & \multicolumn{2}{c|}{ Mammography } \\
\cline { 2 - 7 } & $\mathrm{r}$ & $\mathrm{p}$ & $\mathrm{r}$ & $\mathrm{p}$ & $\mathrm{r}$ & $\mathrm{p}$ \\
\hline $\begin{array}{l}\text { knowledge about } \\
\text { breast cancer }\end{array}$ & 0.47 & $0.0000^{* *}$ & 0.35 & $0.0000^{* *}$ & 0.44 & $0.000^{* *}$ \\
\hline $\begin{array}{l}\text { Receiving } \\
\text { hormonal } \\
\text { contraceptives }\end{array}$ & 0.04 & 0.57 & 0.11 & 0.09 & 0.02 & 0.73 \\
\hline $\begin{array}{l}\text { Had hysterectomy } \\
\text { operation }\end{array}$ & 0.05 & 0.45 & 0.01 & 0.92 & 0.05 & 0.47 \\
\hline Breast problems & 0.126 & $0.0^{*}$ & 0.298 & $0.000^{* *}$ & 0.199 & $0.002^{* *}$ \\
\hline
\end{tabular}

Table (3): Correlation between age at menarche, age at first delivery and menopause with screening practices among the studied sample

\begin{tabular}{|l|c|c|c|c|c|c|}
\hline \multirow{2}{*}{ Age } & \multicolumn{2}{|c|}{ Breast self examination } & \multicolumn{2}{c|}{ Clinical breast examination } & \multicolumn{2}{c|}{ Mammography } \\
\cline { 2 - 7 } & $\mathrm{r}$ & $\mathrm{p}$ & $\mathrm{r}$ & $\mathrm{p}$ & $\mathrm{r}$ & $\mathrm{p}$ \\
\hline Age at menarche & 0.09 & 0.13 & 0.04 & 0.50 & 0.02 & 0.80 \\
\hline Age at first delivery & 0.32 & $0.000^{* *}$ & 0.01 & 0.89 & 0.01 & 0.92 \\
\hline Age at menopause & 0.07 & 0.59 & 0.02 & 0.87 & 0.05 & 0.69 \\
\hline
\end{tabular}

IV. Discussion

Breast cancer is by far the most frequent cancer in women worldwide. It is one of the leading causes of cancer mortality in women and constitutes $15 \%$ of female cancer deaths [16]. Also, the most prominent cause of cancer death among women in low-and middle-income countries is breast cancer, accounting for 269,000 deaths (12.7\% of all cancer deaths) in 2008 [17]. There is variation of breast cancer incidence worldwide in which Africa is not excluded [18]. Incidence of breast cancer varies from 27\% of cancers in North African countries (Algeria and Egypt) to $15 \%$ in sub-Saharan Africa [19]. 
Results of this study revealed that, one third of the sample aged between 20 to less than 30 years and slightly more than one quarter aged between 40 to less than 50 years. A statistically significance negative correlation was found between age of the study sample and their practicing of breast self-examination and clinical breast examination, while no statistically significant correlation was found between age and practicing mammography. In agreement with the study results the American Cancer Society [20] revealed that, the risk of developing breast cancer increases with advanced age and about 1 out of 8 invasive breast cancers were found in women younger than 45 years, while about 2 out of 3 invasive breast cancers were found in women aged 55 years or older.

Moreover, the research done by Aboserea, Abdelgawad and Wafik, [21] to detect breast cancer among newly diagnosed females at Sharqia Governorate, Egypt, revealed that, the most frequent age groups were 30-39 years, 20-29 years and $40-49$ years $(27.9 \%, 24.4 \%$ and $22.1 \%$ respectively) with mean age 38.7 years. Siegel, Ma, Zou and Jemal, [22] revealed that, before 49 years of age the estimated risk of developing breast cancer is $1 / 53$ however, this rises to $1 / 43$ for 50-59 years old and rises again to $1 / 23$ for $60-69$. Significantly, for women aged $>70$ this risk is the highest with a $1 / 15$ chance of developing breast cancer. In agreement with the study results, the studies done in Nigeria by Okolie [23] on females undergraduate and females attending antenatal clinic revealed that, the majority of them $(92.4 \%)$ and $(84.3 \%)$ respectively were practicing breast self-examination.

While Eguvbe, Akpede and Arua, [24] found that age have a significant effect on their breast selfexamination practices. From the researcher point of view it is very difficult to assume that only the age would affect the practice of any breast cancer screening method, it is a matter of many factors as the education, family history, awareness of the problem and so on that might alert the female to the importance of the screening procedures. Yet screening practices as breast self-examination and clinical breast examination might be higher for younger females may be due to the presence of close family member with breast cancer and the experience of any women with breast cancer in their families might alert them to the symptoms and ways of detection.

In relation to educational level, more than one quarter of the study sample had secondary, diploma education and less than one quarter were unable to read and write while very low percentage had university education. A statistically significant positive correlation was found between study sample's education and their breast self-examination and mammography practicing. The same result was found by the study done in Egypt by Ismail, Abd El Hamid and Abd ElNaby [25] to assess factors that hinder early detection of breast cancer among females at Cairo University Hospital and found that more than one quarter of the sample was able to read and write while low percentage had university education. Also the study done by Aboserea et al. [21] revealed that, more than one third of the sample was illiterate and mentioned that, illiteracy constituted knowledge of women about breast cancer. El Shamaa and Hassanein, [26] who studied the risk factors of breast cancer among 84 Saudi women and reported that, educational level of cases ranges from illiterate to secondary school yet, education was found to be a risk factor.

A slightly different result was found by Olowokere, Onibokun and Oluwatosin, [27] who assess rural women's awareness and knowledge of breast cancer and their screening practices in selected rural communities of Nigeria and a significant association was revealed between the educational status of women and their practices for clinical breast examination which means that the higher the educational status of women, the more the likelihood that they are going to participate in screening test for breast cancer. Also a study done by Ozmen et al., (2009) [28] among the Turkish women to clarify the risk for breast cancer, concluded that higher education does not mean that people will follow all the health guidelines because some highly educated people still lack the awareness to make correct health decisions. The study done by Eguvbe et al. [24] among nurses and health care workers in Nigeria found that, educational level was affecting the practice of breast self-examination significantly as highly educated were practicing breast self-examination.

More than half of the study sample was from rural areas. A different results was revealed from Dey, [29] who studied the urban-rural differences of female cancer in Gharbiah, Egypt and found that, breast incidence among 4,794 females in urban areas was higher than rural areas. According to Olowokere et al. [27] who studied females in suburban and urban communities in Nigeria (52.8\% \& 52.8\% respectively) claimed to have heard about breast self-examination. The difference between the two studies could be related to the sample selection.

It was found that, slightly more than half of the study sample delivered for the first time when they were 16 years to less than 20 years while less than half of them aged 20 to less than 25 years when they delivered for the first time with a mean age 20.3 \pm 2.54 years. Almost the same results was found by Ismail et al., [25] where, more than half of the sample aged from 15 to less than 21 years at first full term pregnancy, while $40.2 \%$ aged 21 to less than 26 years and only 2.2\% aged 26 years and more at their first pregnancy among Egyptian females. This finding contradicted with the study done by Buki et al. [30] where women having their first child after 30 years of age, 
have twice risk for breast cancer compared with women having first child before 20 years of age among Egyptian females who got pregnant. Also, the research done by Aboserea et al. [21] revealed that, the most frequent risk factors of breast cancer are first full term pregnancy at 35years. Moreover, American Cancer Society [20] revealed that, women who have not had children or who had their first child after age 30 have a slightly higher breast cancer risk.

Results revealed that, almost one third of the study sample had their menarche at the age from 13 to less than 14 years, more than one quarter had their menarche at the age of 14 years, and less than one quarter had their menarche at the age of 12 years to less than 13 years. As for menopause, about one quarter of the study sample passed through menopause at the age of 55 to 56 years, almost one third had their menopause by the age of 49 year to less than 51 years, slightly more than one third had their menopause by the age of 51 years to less than 53 mean of 52.44 \pm 2.42 years. A higher results was found by Ismail et al., [25] where more than two third of the sample had their menarche at age less than fifteen years while, the majority of the sample aged 41 years to less than 51 years at menopause. In the same direction, American Cancer Society [20] reported that, women who have more menstrual cycles because they started menstruating at an early age (before age 12) and/or went through menopause at a later age (after age 55) had a slightly higher risk of breast cancer. This may be related to a higher lifetime exposure to the hormones estrogen and progesterone. In addition, Said, Abulkheir, Helal and Mohammad, [31] found that, most of cancer patients are postmenopausal constituting $57.5 \%$ of the total sample.

It was found that, about three quarters of the study sample did not have any knowledge about breast cancer. As for the source of their knowledge about breast cancer results revealed that, the majority had their knowledge from television \& radio, family \& friends, newspapers \& magazines and only very few had their knowledge from doctors and nurses. Almost the same results were found in researches where the sources of information varied among the population but the prominent sources were television and radio [32, 33], hospital [ 33], healthcare workers and schools [24, 34], newspaper [24], text books and print media [32], friends and relation [32, 34].

Slightly less than one quarter of the study sample had previous breast problems, in the form of benign lymph nodes, breast collection, and abscess and nipple secretions. A statistically significant relation was found between having previous breast problem and practicing breast self-examination, clinical breast examination and mammography. Opposite of the study results Aniebue \& Aniebue, [35] who studied awareness of breast cancer and breast self-examination among female secondary school teachers in Enugu metropolis, south-eastern Nigeria and found no significant association between previous removals of breast lump with practice of breast self examination. The difference between the two studies could be related to the sample selection but having previous simple breast problem might alert the women to regular checking of her breast.

As for the family history of breast cancer, slightly more than three quarters had no family history of breast cancer, those who had family history of breast cancer indicated that, their mothers were the affected person followed by their aunts (mother's sister), their sisters and their grandmothers. Also, a statistically significance correlation was found between family history of breast cancer and practicing breast self-examination, clinical breast examination and mammography. The same results was obtained from the study done by Ismail et al., [25] where less than one quarter of the sample had previous family history of breast cancer, of those more than two third of had a first-degree relative and also a statistically significant correlation was found between family history of cancer and breast self examination and mammography. Opposite to the study results Aniebue \& Aniebue, [35] who found no significant relationship between family history of breast cancer and practice of breast selfexamination. This difference might be related to the sample characteristics in the two studies. The American cancer society, [20] mentioned that, having a first-degree relative (mother, sister, or daughter) with breast cancer almost doubles a woman's risk of having breast cancer and having two first-degree relatives increases her risk about three-folds. The study done by Madanat and Merrill, [36] who studied breast cancer risk-factor and screening awareness among women nurses and teachers in Amman, Jordan and found that, women with a family history of breast cancer have significantly better general breast cancer knowledge and awareness about breast cancer screening.

Regarding the study sample's knowledge about methods of breast cancer screening and its barriers, results revealed that, about half of them did not have any knowledge about breast self-examination, three quarter never practiced breast self-examination, and above two third of those who were practicing it were doing it once per month, while above quarter were doing breast self-examination only in the presence of complain. A lower result was obtained from different Nigerian studies where $18.1 \%$ had never checked their breast [37]. While in a similar study only $21.8 \%$ had practiced breast self examination [38]. Almost the same results was revealed from the study done by Ismail et al., [25] in Egypt where more than half of the sample has no knowledge about breast self examination, more than two third never practice breast-self examination. The same results was found by Segni, 
Tadesse, Amdemichael \& Demissie, [39] when assess knowledge, attitude and practice of regular breast selfexamination among female health science students of Adama science and Technology University in 2014 the sample mentioned that the frequency of breast self examination monthly. Lack of knowledge is very obvious about screening methods among the study sample and this could be related to the level of awareness of the seriousness of breast cancer.

Regarding barriers for not practicing breast self-examination, results revealed that, having no knowledge was the main cause for not doing breast self-examination, followed by fear from discovering cancer and embarrassment. Ismail, et al. [25] found almost the same results where the majority of the sample identified that lack of knowledge is the main cause for not doing breast-self examination. A slightly higher result was found by Kumar \& Kashyap, [40] in India where 75.9\% were aware of breast cancer. Opposite to the study results Akpo E, Akpo M, Akhator [41] who studied breast cancer in Nigeria found that all the participants (100\%) practiced breast self-examination but only $50 \%$ of them knew how to do it correctly. This difference could be related to many factors as the age differences, education and cultural differences. The studies done by Okolie, [23]; Aniebue \& Aniebue, [35] and Bassey et al., [42] found the reasons for non-performance of breast self-examination were; not having a family history of breast cancer, fear of finding a lump, forgetfulness, ignorance of technique, not considering it necessary and feeling of discomfort at touching the breast.

The majority of the study sample did not practice mammography nor had any knowledge about this procedure. For those who practiced mammography it was done 2 years ago while almost half performed it since 3 years. The main causes for not doing mammography were; embarrassment from the procedure, fear from painful sensation, very expensive procedure, fear from cancer diagnosed, fear from exposure to radiation, and husband refusal. Almost the same was found by Ismail et al. [25] where most of the sample didn't have any knowledge about mammography, but the majority of them performed only when the doctor recommended it and the main causes for not doing mammography were; painful sensation, very expensive procedure, no need for this procedure, embarrassment and a fear from being diagnosed by breast cancer. A different results was found by Oche, Ayodele and Umar [43] aS when assessing the knowledge of female health workers about breast cancer and their attitude and practice o f mammography, $84 \%$ of the respondents were aware of mammography as a way of detecting cancer of the breast with more than half (56\%) having adequate knowledge about mammography and its ability to detect early cancer of the breast. While Gali, [44] found poor uptake of mammography as only (38.6\%) of those within the ages $40-49,(27.3 \%)$ of those within the ages 50-59 had a screening mammography and only one person above 60 year has had screening mammography.

Results revealed that, about three quarters of the study sample did not have clinical breast examination by doctors or nurses while slightly more than one quarter of them had clinical breast examination. Regarding time of clinical breast examination, the majority revealed that, they do it if there is any problem. The result also revealed that, the main causes for not seeking doctors or nurses for clinical breast examination were embarrassment, husband's refusal, fear from being diagnosed by breast cancer and death, financial status, inaccessible of medical services, mistrust and the concept that there is no need for doing this examination. Almost the same result was found by Bello et al. [33] who assessed knowledge and practice of breast cancer screening among female nurses and lay women in Osogbo, Nigeria and revealed that, $26 \%$ of the study subjects have had the procedure in the past one year. A lower result was found by Onwere et al., (2009) [45] when determine antenatal women's knowledge and practice of breast self-examination as a method of early detection of breast cancer only $1 \%$ and $2 \%$ of their respondents had clinical breast examination performed by doctors and nurses. Also the study done by Olowokere et al. [27] found that, clinical breast examination was known among $51.7 \%$ of the women and $31.7 \%$ of them confirmed that they had breast examination by health professionals, however, $38.9 \%$ of the women could not correctly ascertain the ideal frequency for performing the procedure.

In addition, Aboserea et al. [21] found that, lack of doing mammography, annual clinical breast examination and monthly breast-self examination is the main limitations for early diagnosis of breast cancer in Gharbia, Egypt. Moreover, the research done by Al-Dubai, Ganasegeran and Alabsi [46] who explored barriers to breast-self examination among urban women in Malaysia, found that, 55\% practice breast-self examination, among the $45 \%$ of respondents who do not practice breast-self examination, $79.8 \%$ do not know how to do it, $60.6 \%$ fear being diagnosed with breast cancer, 59.6\% are worried about mammography . In Arab countries, females tend to refuse examination by doctors especially for sensitive feminine places due to embarrassment and their culture that taught them not to be touched or expose her body to any males not even to doctors. 
It was found that, only five percent of the study sample had hysterectomy, at the age of 50 years while one quarter had hysterectomy at the age of 55 to less than 60 years. No statistically significant correlation was found between study sample that had hysterectomy and their practice of breast self-examination, clinical breast examination and mammography. A slightly higher result was found by Ismail, et al. [25] where only $10 \%$ of the sample had hysterectomy with a mean age 52.45 \pm 4.762 . According to the study done by Nichols, et al. [47] breast cancer risk is $24-41 \%$ lower in women who have hysterectomy before menopause, compared with women who do not have these surgeries but hysterectomy after menopause may be associated with increased breast cancer risk if estrogen therapy is used after the surgery.

Results revealed that, slightly more than half of the study sample was using hormonal contraceptive methods and no one of them took hormonal replacement therapy after menopause. According to the American cancer society [6] post-menopausal hormone therapy increased the risk in women who use or recently used combined these hormones for many years, and women who recently are using hormonal contraceptives have slightly higher risk than in women who never used them.

Results revealed that, three quarter of the study sample breast feed their children for 2 years. In agreement with the study results some studies suggested that breastfeeding may slightly lower breast cancer risk [6]. Regarding body mass index, it was found that, half of the study sample was overweight, and only eight point eight percent were obese and the rest had normal body mass index and only $28.3 \%$ of the study sample was practicing exercises. Almost the same result was found by Aboserea, et al. [21] where more than 54\% of the studied sample was overweight and obese and concluded that, with increasing obesity among Egyptian population especially females and lack of exercises, this can increase their chances of having breast cancer and that regular exercises tend to lower the levels of estrogen. A higher results was found by Ismail, et al. [25] where more than two third of the sample are obese and the rest had normal body mass index and low percentage was practicing exercises. According to the American cancer society, [20] the presence of breast fatter tissue can increase the chance of getting breast cancer by raising estrogen levels. Before menopause, ovaries produce most of estrogen and fat tissue produces a small amount of estrogen but after menopause most of a woman's estrogen comes from fat tissue.

\section{Conclusion}

The study concluded that, the common breast cancer risk factors identified were; age, education, family history, knowledge about breast cancer are significantly related with screening. Screening for breast cancer is important in the early detection through various methods as breast self examination, clinical breast examination and mammography. Many important breast cancer screening barriers have been identified among this group of Egyptian women and identification of barriers will help to remove those obstacles and design more relevant strategies to increase the utilization of breast screening service and to ensure adequate breast care of these women.

\section{Recommendation}

Based on the findings of this research the following are recommended:-

- Educational program is needed to increase women' awareness about importance of breast cancer screening practices and how and when to do them.

- Expand knowledge about breast cancer prevention through collaborative efforts from the Ministry of Health using mass media to raise the awareness of the women about breast cancer risk factors and screening practices.

- Counseling should be given for all women by health professionals about risk factors for breast cancer and methods for early detection.

[1]. Al-Zalabani A. H., Alharbi K. D., Fallatah N.I., Alqabshawi R.I. \& Al-Zalabani A.A. \& Alghamdi. S. M. (2016). Breast Cancer Knowledge and Screening Practice and Barriers Among Women in Madinah, Saudi Arabia. American Association for Cancer Education.

[2]. Bray F., Ren J.S., Masuyer E., Ferlay J. (2013).Global cancer prevalence for 27 sites in the adult population. Int J Cancer; 132(5): $1333-1145$.

[3]. Faronbi J.O., Abolade, J. (2012). Breast Self Examination practices among female secondary school teachers in a rural community in Oyo State, Nigeria. Open Journal of Nursing; 2: 111-115.

[4]. Shrivastava S.R., Shrivastava P.S. \& Ramasamy J. (2013). Breast- Self Examination: A Tool for Early Diagnosis of Breast Cancer American Journal of Public Health Research 2013; 1 (6): 135-139.

[5]. Adesunkanmi A.R., Lawal O.O., Adelusola K.A. \& Durosimi M.A. (2013). The severity, outcome and challenges of breast cancer in Nigeria. Epub 15 (3): 399-409.

[6]. American Cancer Society, (2017). Breast Cancer, Reviewed February. 
[7]. Mamdouh H.M. El-Mansy, H., Kharboush, I. F., Ismail, H,M. Tawfik, M. M., Abdel El-Baky, M., El Sharkawy, O.G. (2014). Barriers to breast cancer screening among a sample of Egyptian females. Journal of Family and Community Medicine; 21 ( 2):119124.

[8]. Kharboush, I. F., Ismail, H.M. Kandil, A.A., Mamdouh,H.M., Muhammad, Y.Y., El Sharkawy, O.G., Sallam,H.N.(2011). Raising the Breast Health Awareness amongst Women in an Urban Slum Area in Alexandria, Egypt. Breast Care; 6:375-379

[9]. Ginseng G.M., Lauer J.A., Zelle S., Baeten S., Baltussen R.(2012). Cost effectiveness of strategies to combat breast, cervical, and colorectal cancer in Sub-Saharan Africa and South East Asia: Mathemetical modelling study. BMJ; 344- 347.

[10]. American Cancer Society. (2015). Breast Cancer Prevention and Early Detection.Available:http://www.cancer.org/cancer/breastcancer/moreinformation/breastcancerearlydetection/breast-cancerearlydetection-acs-recs-bse. Last accessed 27 February.

[11]. Saudi cancer Registry Report. (2012). Saudi cancer Registry, Saudi oncology Society. Available from: http://www.scr.org.sa/reports/ ScR .pdf. Last accessed May 14.

[12]. Alkhasawneh I.M., Akhu-Zaheya L.M. \& Suleiman S. M. (2009). Jordanian nurses' knowledge and practice of breast selfexamination. J Adv Nurs; 65:412-416.

[13]. Ibrahim, A. S., Khaled, M.H., Mikhail, N.H.,Baraka, H. \& Kamel, H. (2014). Cancer Incidence in Egypt: Results of the National Population-Based Cancer Registry Program. Journal of Cancer Epidemiology; 18 page.

[14]. Shields, P. and Rangarjan, N. (2013). A Playbook for Research Methods: Integrating Conceptual frameworks and Project Management. Available at http://www.open library.com

[15]. The Ministry of State for Administrative Development. (2014). General Directorate for Information and Documentation; online portal for Cairo Governorate.

[16]. Torre, L.A.1., Bray, F., Siegel, R.L., Ferlay, J., Lortet-Tieulent, J., \& Jemal, A. (2015). Global cancer statistics. CA Cancer J Clin; 65:87-108.

[17]. Lancet, T. (2011). The good news about cancer in developing countries. Lancet 378(9803):1605.

[18]. Ayoola, O. A. and Oyedunni S.A.(2016). Breast cancer knowledge and screening practices among female secondary schools teachers in an urban local government area, Ibadan, Nigeria. Journal of Public Health and Epidemiology; 8(5), pp. 72-81.

[19]. Ayoola, O.A., Taiwo, O., Oyedunni, A.S. \& Tunde O. (2016). Breast cancer awareness, attitude and screening practices in Nigeria: A systematic review. Clin. Rev. Opinions; 7(2), pp. 11-25.

[20]. American Cancer Society, (2011). Breast Cancer Facts and Figures. Atlanta,

[21]. Aboserea, M., M. Abdelgawad and W. Wafik, (2012). Early Detection of Breast Cancer among Females at Fakous District, Sharqia Governorate, Egypt. Life Science Journal, 8(1): 196-203.

[22]. Siegel, R., Ma, J., Zou Z. \& Jemal, A. (2014). Cancer statistics. CA Cancer J. Clin; 64, 9-29.

[23]. Okolie UV (2011). Breast self-examination among female undergraduates in Enugu, Southeast, Nigeria. Int. J. Nurs. Midwifery 4(1):1-7.

[24]. Eguvbe, A., O., Akpede, N., \& Arua, N., E. (2014). Knowledge of Breast Cancer and Need for its Screening Among Female Healthcare Workers in Oshimili South Local Government Council Area of Delta State, Nigeria. Afrimedic J; 5(1):59-64.

[25]. Ismail, G., M., Abd El Hamid, A., A., \& Abd ElNaby, A., G., (2013). Assessment of Factors that Hinder Early Detection of Breast Cancer among Females at Cairo University Hospital. World Applied Sciences Journal; 23 (1): 99-108.

[26]. El Shamaa, E.T. \& Hassanein, M.H. (2012). Risk Factors of Breast Cancer in Abha City: A Case Control Study. Academic Research Internationa; 2 (2):34-41.

[27]. Olowokere, A.E., Onibokun, A.C. \& Oluwatosin, A.O.(2012). Breast cancer knowledge and screening practices among women in selected rural communities of Nigeria. Journal of Public Health and Epidemiology; 4(9): pp. 238-245.

[28]. Ozmen, V., B. Ozcinar, H. Karanlik, N. Cabioglu, M. Tukenmez, R. Disci, T. Ozmen, A. Igci, M. Muslumanoglu, M. Kecer and A. Soran, (2009). Breast cancer risk factors in Turkish women- University Hospital based nested case control research, World Journal of Surgical Oncology; 7: 37.

[29]. Dey, S., (2009). Urban-Rural Differences of Female Cancer in Gharbiah, Egypt. Ph.D. thesis, University of Michigan.

[30]. Buki, L.,P., Garcés, D.,M., Hinestrosa, M., C., Kogan, L., Carrillo, I.,Y.\& French, B. (2008). Latina breast cancer survivors' lived experiences: diagnosis, treatment, and beyond. Cultur Divers Ethnic Minor Psychol. Apr; 14(2):163-7.

[31]. Said, A.F.M., Abulkheir, I.I.H. Helal A. and Mohammad, D.B. (2012). Detection of CK19 mRNA in the blood of breast cancer Female Egyptian patients and its relation to established prognostic parameters. Life Science Journal, 9(1).

[32]. Salaudeen AG, Akande TM and Musa OI (2009). Knowledge and Attitudes to Breast Cancer and Breast Self-Examination among Female Undergraduates in a State in Nigeria. Eur. J. Soc. Sci. 3:157-165.

[33]. Bello, T., O., Olugbenga-Bello, A.,I., Ogunsola, A.,S., Adeoti, M.,L. \& Ojemakinde, O.,M. (2011). Knowledge and practice of breast cancer screening among female nurses and lay women in Osogbo, Nigeria. West Afr. J. Med. 30(4):296-300.

[34]. Omotara B, Yahya S, Amodu M, Bimba J. (2012). Awareness, attitude and Practice of Rural women regarding Breast Cancer in Northeast and Practice of Rural women regarding Breast Cancer in Northeast Nigeria. J Commun. Med. Health Educ; 2:148.

[35]. Aniebue, P.,N.\& Aniebue, U.,U. (2008). Awareness of breast cancer and breast self-examination among female secondary school teachers in Enugu metropolis, south-eastern Nigeria. Int. J. Med. Health Dev; 13(2):105-110.

[36]. Madanat H. \& Merrill RM. (2002). Breast cancer risk-factor and screening awareness among women nurses and teachers in Amman, Jordan. Cancer Nursing; 25(4):276-82.

[37]. Balogun MO, Owoaje ET (2005). Knowledge and practice of breast self-examination among female traders in Ibadan, Nigeria. Ann. Ibadan Postgrad. Med; 3(2):52-56.

[38]. Obaji N, Elom H, Agwu U, Nwigwe C, Ezeonu P, and Umeora O. (2013). Awareness and practice of breast self- examination among market women in Abakaliki, South East Nigeria. Ann. Med. Health Sci. Res; 3(1): 7-12.

[39]. Segni, M.T. , Tadesse, D.M., Amdemichael, R. and Demissie H.F. (2016).Breast Self-examination: Knowledge, Attitude, and Practice among Female Health Science Students at Adama Science and Technology University, Ethiopia. Gynecology \& Obstetrics

[40]. Kumar M, Kashyap VM (2016). Awareness about breast cancer among women attending obstetrics and gynaecology department in a tertiary care hospital of Jharkhand, India. Int. J. Commun. Med. Public Health; 3(4):938-943.

[41]. Akpo EE, Akpo MO, Akhator A (2010). Breast cancer knowledge and screening practices among Nigerian medical students. Internet J. Health; 11(2). 
[42]. Bassey R., B., Irurhe, N., K., Olowoyeye, M. A., Adeyomoye, A., A., Onajole, A., T. (2011). Knowledge, attitude and practice of breast self examination among nursing students in Lagos University Teaching Hospital, Nigeria. Educ. Res; 2(6):1232-1236.

[43]. Oche MO, Ayodele SO, Umar AS (2012). Knowledge of female health workers about breast cancer and their attitude and practice of mammography. Public Health Res. 2(5):114-119.

[44]. Gali BM (2013). Breast cancer awareness and screening practices among femalehealth workers of university of Maiduguri teaching hospital. BOMJ; 10(2).

[45]. Onwere S, Okoro O, Chigbu B, Aluka C, Kamanu C, Onwere A (2009). Breast self- examination as a method of early detection of breast cancer: Knowledge and practice among antenatal clinic attendees in South Eastern Nigeria. Pak. J. Med. Sci. 25:122- 5.

[46]. Al-Dubai SAR, Ganasegeran K and Alabsi AM, et al. (2012). Exploration of barriers to breast-self examination among urban women in Shah alam, malaysia: a cross sectional study. Asian Pac J Cancer Prev; 13:1627-1632.

[47]. Nichols HB, Trentham-Dietz A, Newcomb PA, Titus LJ, Egan KM, Hampton JM, Visvanathan K. (2013) Pre-diagnosis oophorectomy, estrogen therapy and mortality in a cohort of women diagnosed with breast cancer. Breast Cancer Res 15: R99. 